\title{
Matrix Metalloproteinases (MMP-2,-3,-9) Gene Polymorphisms in Cases of Benign Vocal Fold Lesions and Laryngeal Carcinoma
}

\author{
VYKINTAS LIUTKEVICIUS ${ }^{1}$, VAIVA LESAUSKAITE ${ }^{2}$, RASA LIUTKEVICIENE $^{3}$, \\ PAULIUS VAICIULIS ${ }^{1}$ and VIRGILIJUS ULOZA ${ }^{1}$
}

\author{
${ }^{1}$ Department of Otolaryngology, Lithuanian University of Health Sciences, Kaunas, Lithuania; \\ ${ }^{2}$ Laboratory of Molecular Cardiology in the Institute of Cardiology, \\ Lithuanian University of Health Sciences, Kaunas, Lithuania; \\ ${ }^{3}$ Neuroscience Institute, Lithuanian University of Health Sciences, Kaunas, Lithuania
}

\begin{abstract}
Background/Aim: The matrix metalloproteinases (MMP) play an important role in the physiological and pathological remodeling of tissues including carcinogenesis. The study's aim was to assess the relations between MMP-2(735C/T), MMP-2(-1306C/T), MMP-9(-1562C/T), and MMP3(-11715A/6A) polymorphisms, and clinical/morphological manifestation of laryngeal squamous cell carcinoma (LSCC) and benign vocal fold lesions (BVFL). Patients and Methods: Two hundred and seventeen patients with LSCC and BVFL and 458 controls were included in this study. The genotyping was performed using the real-time polymerase chain reaction method. Results: The MMP-2(-1306C/T) C/T genotype was significantly rarer among the patients with moderate-poorly differentiated LSCC compared to the control group, however the MMP-3(-11715A/6A) 6A/6A genotype was significantly more frequent compared to controls. Smoking and $6 A / 6 A$ genotype of MMP-3(-11715A/6A) polymorphism were associated with increased odds of LSCC risk. No associations between MMP genotypes and BVFL were found. Conclusion: Smoking and MMP-3 (-11715A/6A) 6A/6A genotype may cause a higher risk for developing $L S C C$.
\end{abstract}

Head and neck squamous cell carcinoma (HNSCC), which includes tumors of the oral cavity, pharynx, hypopharynx,

This article is freely accessible online.

Correspondence to: Vykintas Liutkevicius, Department of Otolaryngology, Lithuanian University of Health Sciences, Eiveniu 2, LT-50009, Kaunas, Lithuania. Tel: +37 037326862, e-mail: vykintas.liutkevicius@1smuni.lt

Key Words: Laryngeal squamous cell carcinoma, matrix metalloproteinases, gene polymorphism, benign vocal fold lesions. and larynx is one of the most common cancers worldwide (1). Laryngeal squamous cell carcinoma (LSCC) constitutes approximately $2-3 \%$ of all malignant tumors representing the most common neoplasm of the head and neck region. According to the morbidity rate, LSCC ranks second among the neoplasms of the respiratory system after lung cancer (2). Despite the current advances in diagnostics, surgery, radiotherapy and chemotherapy, there was no significant increase in the 5-year survival rate in the last few decades (3). Following LSCC treatment, the quality of life of patients in advanced stages of the disease often remains significantly impaired, manifesting with dysphagia and loss of voice and speech (4).

The laryngeal carcinoma does not occur in unaltered tissues. It is formed under the influence of harmful habits when hyperplastic (dysplasia, atypia) changes emerge in squamous cell epithelium. Many factors, such as smoking, alcohol use, HPV infection, and genetic predisposition are associated with an increased risk of LSCC (5). Although tobacco and alcohol addiction play a critical role in LSCC carcinogenesis, only a small proportion of smokers and drinkers are finally diagnosed with LSCC. This leads to presuming that genetic susceptibility to LSCC may vary in the general population (6).

The important role of matrix metalloproteinases (MMPs) in HNSCC development has been established in the last decades (7). MMPs belong to a family of zinc-containing enzymes which are responsible for degrading all extracellular matrix components, which is a very important event during the cancer cell invasion process and metastasis of most neoplasms (8). MMPs represent the endopeptidases that contain an active site $\mathrm{Zn}^{2+}$ and are divided into subfamilies based on relationships and structure of the catalytic domain. MMPs encompass a family of currently 25 related, yet distinct vertebrate gene products of which 23 are found in 
humans (9). Under normal conditions, MMPs are involved in both wound repair, tissue regeneration, and reproduction (10). MMPs may also be implicated in the carcinogenesis process, as previous studies have shown that MMPs may play a role in several steps of cancer development, including cancer cell growth, differentiation, migration, apoptosis, invasion, and metastasis (11). Typically, MMPs may be divided into the following five groups: i) collagenases (MMP-1,-8,-13), ii) gelatinases (MMP-2,-9), iii) stromelysins (MMP-3,-10), iv) membrane MMPs (MMP-14,-15,-16,-17), and v) others (MMP-19,-21,-23A,-23B,-27,-28) (9).

MMP-2, MMP-9, and MMP-3 represent the key members of the MMPs family and have been found to play a crucial role in physiological and pathological events associated with the metabolism and remodelling of the connective tissue (12, 13). Overexpression of these MMPs has been found to be associated with the development of different cancer types, including HNSCC (7), thereby indicating that these MMPs may also be implicated in the development of LSCC. The role of MMP-2 and MMP-9 in LSCC tumorigenesis has been investigated in numerous studies (14-16), however there is only one study analysing laryngeal carcinoma association with MMP-3 (17). To the best of our knowledge, there is no literature data analysing MMP-2 (-735 C/T), MMP-2 (-1306 $C / T)$, MMP-9 (-1562 C/T), and MMP-3 (-1171 5A/6A) gene polymorphism associations with LSCC and non-malignant laryngeal lesions.

The aim of the study was to assess the relations between MMP-2 (-735 C/T), MMP-2 (-1306 C/T), MMP-9 (-1562 $C / T)$, and MMP-3 (-1171 5A/6A) gene polymorphisms and the LSCC and non-malignant laryngeal lesions as well as their clinical and morphologic manifestations.

\section{Patients and Methods}

Patients. The research protocol of the present study was approved by the Kaunas Regional Biomedical Research Ethics Committee (Protocol No. BE-2-34). The total study group consisted of 217 LSCC and benign vocal fold lesions (BVFL) patients who underwent treatment at the Department of Otolaryngology of Lithuanian University of Health Sciences (LUHS) and the Oncological Hospital of the LUHS.

The BVFL group consisted of 105 patients and included the following clinical entities: i) vocal fold polyps (VFP) $(n=39$, age: 43 , range $=21-69)$, ii $)$ laryngeal keratosis $(\mathrm{LK})(\mathrm{n}=36$, age:54, range $=34-78)$, and recurrent respiratory papillomatosis (RRP) subgroup $(n=30$, age: 38 , range $=21-83)$. The clinical diagnosis of BVFL was based on typical clinical signs revealed during video laryngostroboscopy (VLS) and direct microlaryngoscopy. All patients underwent endolaryngeal microsurgery; therefore, the final diagnosis was confirmed using the results of histological examination of the removed mass lesions from the larynx.

The LSCC group consisted of 105 males and 7 females who received no treatment prior to being diagnosed with $\operatorname{LSCC}(n=112)$.
The age of LSCC group patients ranged from 36 to 79 years (median 62 years). Clinical diagnosis of LSCC was based on the findings of VLS and direct microlaryngoscopy. The final diagnosis was confirmed following histopathological investigation. The patients of the LSCC group underwent standard additional diagnostic tests, including: chest x-ray, abdomen ultrasonography, and computed tomography (CT) of the neck. The subjects with previously diagnosed malignant tumors in other body locations were not involved into the study. The most important clinical and pathological features of BVFL and LSCC patients are presented in Tables I and II.

The reference group consisted of random research samples from Kaunas city (Lithuania) residents who were selected during the HAPPIE (The international Health, Alcohol and Psychosocial Factors in Eastern Europe project) study (18). This reference group was used in the present study to compare the genotypic distribution of MMP gene polymorphisms. The samples were collected in the Population Study Laboratory at the Institute of Cardiology of LUHS by carrying out a selection based on the lists of residents of Kaunas city. Totally, 1128 residents of Kaunas within the age group from 45 to 73 years (median: 60 years) participated in the HAPPIE study. The reference group for this study was formed by selecting 428 men and 30 women within the age group from 45 to 73 years (median: 62 years) from the HAPPIE study. The reference group was created by taking into consideration the distribution of age and gender in the LSCC group. Therefore, the medians of the patient age of the reference group and the LSCC group did not differ significantly $(p>0.05)$.

DNA extraction. The DNA extraction and genotyping were carried out at the Laboratory of Molecular Cardiology at the Institute of Cardiology of LUHS. Briefly, $10 \mathrm{ml}$ of blood were withdrawn from a peripheral vein for each study participant, and DNA was extracted using the Genomic DNA Purification Kit (Fermentas, Vilnius, Lithuania) according to the recommendations of the manufacturer or the silica gel column method utilizing the genomic DNA extraction kit SorpoClean ${ }^{\mathrm{TM}}$ Genomic DNA Extraction Module (SORPO Diagnostics, Vilnius, Lithuania) according to the manufacturer's protocol (Metabion, Planegg, Germany). The genotyping of MMP-3 (-1171 5A/6A), MMP-2 (-735 C/T), MMP$2(-1306 C / T)$, and MMP-9 $(-1562 C / T)$ was carried out using the real-time polymerase chain reaction (PCR) method. For the genotyping of MMP-2 (-735 C/T) (rs2285053) and MMP-2 (-1306 $C / T$ ) (rs243865) Applied Biosystems (Thermo Fisher Scientific, San Jose, CA, USA) kits were used. Genotyping was performed using the HT 7900 real-time PCR quantification system (Applied Biosystems). The real-time $\mathrm{PCR}$ reagents $\left(2 \mathrm{X}\right.$ Maxima $^{\mathrm{TM}}$ Probe/ROX qPCR Master mix buffer, fluorescent dye-labelled markers, sterile $\mathrm{ddH}_{2} \mathrm{O}$ ) were taken out of $-20^{\circ} \mathrm{C}$ and were thawed at room temperature. The thawed reagents were centrifuged $(10,000$ rpm) and were stored in an ice tub for setting up the RT PCR reactions. The PCR mixture $(9 \mu \mathrm{l})$ was poured into each well of a 96-well microtiter plate, and then $1 \mu \mathrm{l}$ of matrix DNA of samples $(\sim 10 \mathrm{ng})$ and $1 \mu \mathrm{l}$ of a negative control $(-\mathrm{K})$ were added. An optic film was pasted on the microtiter with the 96 wells, and the microtiter was centrifuged for $15 \mathrm{~s}$ at $10,000 \mathrm{rpm}$. The remaining procedure was continued according to the manual provided by the manufacturer.

A detailed description of the genotyping methods used in the present research have been presented in previous studies $(19,20)$. 
Statistical analysis. For our statistical analysis, the program PASW Statistics 20.0 (SPSS Inc., Chicago, IL, USA) was used. The Hardy - Weinberg analysis was performed to compare the observed and expected MMP's genotype frequencies using $\chi^{2}$ test in all groups. The distribution of the MMP's single nucleotide polymorphism (SNP) between the patients and the reference groups were compared using either $\chi^{2}$ test or Fisher's exact test. Relation of smoking risk and genotype in the LSCC patients' group was analysed by odds ratios (OR) and $95 \%$ confidence intervals $(95 \% \mathrm{CI})$. The significance level of 0.05 was chosen for testing statistical hypotheses.

\section{Results}

The distributions of MMP-3 (-1171 5A/6A), MMP-2 (-735 $C / T)$, MMP-2 (-1306 C/T), and MMP-9 (-1562 C/T) genotypes promoter polymorphisms in BVFL, LSCC and reference groups were in agreement with the Hardy - Weinberg equilibrium $\left(\chi^{2}<3.84, p>0.05\right)$.

The distribution of MMP-3 (-1171 5A/6A), MMP-2 (-735 $C / T)$, MMP-2 (-1306 C/T), and MMP-9 (-1562 C/T) gene polymorphisms among the patients from BVFL group did not differ significantly $(p>0.05)$ from the reference group. The MMP-2 (-1306 C/T) C/T genotype was significantly more rare among the LSCC patients compared to the reference group $(p=0.04)$. However, in the LSCC patients group only a tendency of more frequent MMP-3 (-1171 $5 \mathrm{~A} / 6 \mathrm{~A}) 6 \mathrm{~A} / 6 \mathrm{~A}$ genotype polymorphism was revealed compared to the reference group $(p=0.059)$. For the patients who were diagnosed with advanced stages of LSCC (III-IV), their distribution of genotype MMP-3 (-1171 5A/6A) showed a significantly more frequent $6 \mathrm{~A} / 6 \mathrm{~A}$ genotype $(p=0.004)$ and a more frequent presence of the $6 \mathrm{~A}$ allele $(p=0.041)$ compared to the genotype and allele distribution of the reference group. A similar outcome was revealed after determining a significantly more frequent $6 \mathrm{~A} / 6 \mathrm{~A}$ genotype in the moderate and poorly (G2-3) differentiated LSCC group compared to the reference group $(p=0.017)$. The MMP-2 (-1306 C/T) C/T genotype was significantly more rare among the patients with moderate and poorly (G2-3) differentiated LSCC compared to the reference group $(p=0.007)$. Compared to genotypes of the reference group, MMP-2 (-735 C/T) and MMP-9 (-1562 C/T) genotypes of the LSCC group did not differ. The results of genotypic distributions among LSCC and reference groups are presented in Table III.

Having applied the logistic regression model, the possibility to develop LSCC appeared to significantly depend on the habit of smoking and the MMP-3 (-1171 $5 A / 6 A)$ genotype $6 \mathrm{~A} / 6 \mathrm{~A}$. The possibility of the LSCC development for smoking individuals was 7.69 fold higher compared to non-smokers $(\mathrm{OR}=7.69,95 \% \mathrm{CI}=4.63-1.77$, $p=0.0001$ ), and for those with MMP-3 6A/6A genotype it increases 1.78 fold compared to the $5 \mathrm{~A} / 5 \mathrm{~A}$ or $5 \mathrm{~A} / 6 \mathrm{~A}$ genotypes $(\mathrm{OR}=1.7895 \% \mathrm{CI}=1.08-2.93, p=0.022)$.

\section{Discussion}

Expression of MMPs has already been investigated in numerous studies and in a large variety of different tumors, including different locations of squamous cell carcinoma. Nevertheless, in LSCC, the correlations between the expression of MMPs, morphological parameters of the tumor and clinical signs still remain controversial; moreover, prognostic roles of different MMPs in LSCC have not been established as yet (21-25).

Activation of MMPs expression can be caused by various gene polymorphisms in promoter regions, when their binding to transcription factors or other regulating elements is disrupted. MMP polymorphisms can be induced by nucleotide changes in promoter regions by insertions, substitutions or microsatellite instability (12). In around $90 \%$ of cases, a SNP is determined in the locus where one of the basic changes appears in the DNA strain. Polymorphisms can also be detected in MMP gene promoter regions but most of them are not biologically active. Only a small part of SNPs that can change gene transcription intensity is biologically active and can have an impact on the predisposition of a disease (26).

It has been previously established that MMP-2 -1306 C/T transition in promoter regions consequently changes their activity. Experiments provided by Price' team have shown that the $\mathrm{C}$ allele increases MMP-2 expression more significantly compared to the T allele (27). Similarly, C/T transition located in the MMP-2 -735 promoter region can lead to the same effect (28). Yu et al., have studied Chinese patients with esophageal squamous cell carcinoma carrying the $-1306 \mathrm{C} / \mathrm{T}$ and $-735 \mathrm{C} / \mathrm{T}$ polymorphisms in the MMP-2 promoter region. The authors describe the direct important associations between the haplotype $\mathrm{C}(-1306)-\mathrm{C}(-735)$ and an increased risk of esophageal cancer (29). Penget et al., have confirmed this association in a meta-analysis study (30). In this study, the MMP-2 -735 CC genotype carriers had a higher risk of esophageal and lung cancer compared to those with TT and CT genotypes; the MMP-2 -1306 CC genotype carriers were in higher risk of esophageal, lung, gastric, and head-neck cancer comparing to TT and CT carriers (30). In 2015, Kim et al. conducted a large metaanalysis of sixteen case-control studies with 11792 individuals of MMP-2 (-735 C/T) SNP. The results of this study demonstrated significant associations of the $\mathrm{C} / \mathrm{C}$ genotype with increased cancer risk in the Caucasian population, however, overall MMP-2 (-735 C/T) polymorphism has not been found to be associated with cancer risk in any calculated model (31). In the present study, analysis of MMP-2 (-735 C/T) genotypes distribution did not show any statistically significant relations with LSCC risk, however the MMP-2 (-1306) C/T genotype was significant rarer in LSCC patients compared to healthy controls. 
Table I. The main clinical characteristics of benign vocal fold lesions (BVFL) patients' group.

\begin{tabular}{|c|c|c|c|}
\hline Clinical characteristics & VFP n & LK n & RRP n \\
\hline Number of patients & 39 & 36 & 30 \\
\hline Gender (male/female) & $20 / 19$ & $30 / 6$ & $20 / 10$ \\
\hline Age in years $(\min / \max /$ median $)$ & $21 / 69 / 43$ & $34 / 78 / 54$ & $21 / 83 / 38$ \\
\hline Smoking (smokers/not smokers) & $16 / 23$ & $23 / 13$ & $8 / 22$ \\
\hline The duration of smoking in years ( $\mathrm{min} / \mathrm{max} /$ median) & $4 / 30 / 16$ & $8 / 60 / 30$ & $3 / 40 / 14$ \\
\hline Number of smoked cigarettes per day (min/max/median) & $5 / 20 / 12$ & $5 / 40 / 20$ & $5 / 40 / 20$ \\
\hline Alcohol (users/not users) & $3 / 36$ & $8 / 28$ & $5 / 25$ \\
\hline
\end{tabular}

VFP: Vocal fold polyp; LK: laryngeal keratosis; RRP: recurrent respiratory papillomatosis.

The MMP-9 (-1562 C/T) polymorphism was described for the first time by Zhang et al. in 1999. The authors found that the $\mathrm{C}$ to $\mathrm{T}$ allele substitution in the MMP-9 promotor region may increase the promotor activity by 1.5 -fold (32). In later study, increased $\mathrm{T}$ allele frequency in 152 oral squamous cell carcinomas (OSCC) was detected by Vairaktaris et al. (33). $\mathrm{Tu}$ et al. from Taiwan, have investigated the possible associations between the MMP-9 (-1562 C/T) polymorphism, OSCC and oral submucosal fibrosis (OSF) in areca users. The authors concluded that the $\mathrm{T}$ allele influenced the OSCC risk only in younger areca chewers (34). Similarly, in 2011, Chaudhary et al. described their results from a genetic investigation in OSCC and OSF patients in an Indian population. They evaluated MMP-2 (-1306 C/T) and MMP$9(-1562 C / T)$ polymorphisms in 1260 individuals; 422 patients with HNSCC, 412 patients with OSF, and 426 controls, and identified a strong association between the $\mathrm{T}$ allele of both gene polymorphisms and HNSCC risk in comparison to controls, however, this was not the case with OSF (35). The interesting results were presented by Liu et $a l$. in meta-analysis study. Significant associations between the MMP-9 (-1306 C/T) polymorphism and the risk of different cancer types metastases were found only with the $\mathrm{C} / \mathrm{T}$ genotype. The results from the Asian population showed that the $\mathrm{C} / \mathrm{T}$ and $\mathrm{T} / \mathrm{T}$ genotypes had a higher risk of cancer metastases in comparison to $\mathrm{C} / \mathrm{C}$. In contrast, no such association was found in the European population (36). On the other hand, in study done by Nasr et al. in 2007, no significant association between the MMP-9 (-1306 C/T) polymorphism and nasopharyngeal carcinoma was found (37). This is in agreement with the results of the present study, where the distribution of the MMP-9 (-1306 C/T) genotypes in patients with LSCC did not differ significantly compared to the reference group.

The literature concerning the effect of both MMP-3 expression and its polymorphisms on HNSCC carcinogenesis is scarce and inconsistent. Until now only a few studies have investigated the MMP-3 (-1171 5A/6A) polymorphisms
Table II. The main clinical/pathological characteristics of laryngeal squamous cell carcinoma (LSCC) patients' group.

\begin{tabular}{lc}
\hline Characteristics & $\mathrm{N}$ \\
\hline Number of patients & 112 \\
Gender (male/female) & $105 / 7$ \\
Age in years (min/max/median) & $36 / 79 / 62$ \\
Smoking (smokers/not smokers) & $88 / 24$ \\
The duration of smoking in years (min/max/median) & $7 / 50 / 32$ \\
Number of smoked cigarettes per day (min/max/median) & $3 / 40 / 20$ \\
Alcohol (users/not users) & $58 / 54$ \\
Stage (0/I/II/III/IV) & $4 / 34 / 23 / 30 / 21$ \\
Stage group (St0-StI-StII/StIII-StIV) & $61 / 51$ \\
Tumor (Tis/T1/T2/T3/T4) & $4 / 35 / 26 / 31 / 16$ \\
Tumor group (Tis-T1-T2/T3-T4) & $65 / 47$ \\
Lymph node status (N0/N1/N2/N3) & $96 / 8 / 7 / 1$ \\
Lymph node status group (N0/N1-N2-N3) & $96 / 16$ \\
Tumor differentiation grade (G1/G2/G3) & $56 / 48 / 4$ \\
Tumor differentiation grade group (G1/G2-G3) & $56 / 52$ \\
\hline
\end{tabular}

concerning the different head and neck region tumors. A common variant in the promoter region of the human MMP-3 gene with 1 allele having a run of 5 adenines (5A) and the other having 6 adenines (6A) have been revealed as manifesting an impact on gene expression (38). MMP-3 gene is located in chromosome 11 (11q22.2-11q22.3 region). Insertion of one adenine $(\mathrm{A})$ in the -1171 base-pair position of MMP-3 promoter causes a formation of 6 adenines (6A) instead of $5(5 \mathrm{~A})$. It has been shown that the $6 \mathrm{~A}$ allele has a higher binding affinity for the ZBP-89 transcription factor, which decreases both promoter transcription activity and MMP-3 gene expression (38). Chaudhary et al., have evaluated the MMP-3 (-1171 5A/6A) polymorphism in 362 participants: i) 101 cases of OSF, ii) 135 cases HNSCC and iii) 126 healthy controls. This study found that the $5 \mathrm{~A}$ allele might play an important role in the susceptibility to HNSCC, as individuals with the $5 \mathrm{~A} / 5 \mathrm{~A}$ genotype had nearly a two-fold risk of HNSCC 
Table III. Genotype and allele frequencies of the MMP-2 (-735 C/T), MMP-2 (-1306 C/T), MMP-9 (-1562 C/T), and MMP-3 (-1171 5A/6A) in LSCC patients and reference groups.

\begin{tabular}{|c|c|c|c|c|c|c|c|c|c|c|c|c|}
\hline Gene & $\begin{array}{l}\text { Genotype/ } \\
\text { allele }\end{array}$ & $\begin{array}{c}\text { LSCC } \\
\mathrm{n}(\%)\end{array}$ & $\begin{array}{c}\text { Reference } \\
\text { group } \\
\text { n }(\%)\end{array}$ & $p$-Value & $\begin{array}{c}\text { LSCC } \\
\text { (St 0-I-II) } \\
\text { n }(\%)\end{array}$ & $\begin{array}{c}\text { LSCC } \\
\text { (St III-IV) } \\
\text { n }(\%)\end{array}$ & $\begin{array}{l}\text { Reference } \\
\text { group } \\
\text { n }(\%)\end{array}$ & $p$-Value & $\begin{array}{c}\text { LSCC } \\
\text { G1 } \\
\text { n (\%) }\end{array}$ & $\begin{array}{c}\text { LSCC } \\
\text { G2-3 } \\
\text { n (\%) }\end{array}$ & $\begin{array}{l}\text { Reference } \\
\text { group } \\
\text { n }(\%)\end{array}$ & $p$-Value \\
\hline \multirow[t]{5}{*}{ MMP-2 (-735 C/T) } & $\mathrm{C} / \mathrm{C}$ & $84(77.8)$ & 351 (76.6) & & 49 (79) & $35(76.1)$ & $351(76.6)$ & & $42(77.7)$ & 39 (76.4) & 351 (76.6) & \\
\hline & $\mathrm{C} / \mathrm{T}$ & $22(20.3)$ & 99 (21.7) & 0.89 & $11(17.7)$ & $11(23.9)$ & $99(21.7)$ & 0.97 & $11(20.4)$ & $11(21.6)$ & $99(21.7)$ & 0.99 \\
\hline & $\mathrm{T} / \mathrm{T}$ & $2(1.9)$ & $8(1.7)$ & & $2(3.3)$ & $0(0)$ & $8(1.7)$ & & $1(1.9)$ & $1(2)$ & $8(1.7)$ & \\
\hline & $\mathrm{C}$ & $95(88)$ & $400(87.3)$ & 1 & $54(87)$ & $40(87)$ & $400(87.3)$ & 0.99 & 47 (87) & $44(86)$ & $400(87.3)$ & 0.85 \\
\hline & $\mathrm{T}$ & $13(12)$ & $58(12.7)$ & & $8(13)$ & $6(13)$ & $58(12.7)$ & & 7 (13) & 7 (14) & $58(12.7)$ & \\
\hline \multirow[t]{5}{*}{ MMP-2 (-1306 C/T) } & $\mathrm{C} / \mathrm{C}$ & $73(67.6)$ & $267(58.3)$ & & $41(66.1)$ & $32(69.6)$ & $267(58.3)$ & & $34(63)$ & $37(72.6)$ & $267(58.3)$ & \\
\hline & $\mathrm{C} / \mathrm{T}$ & $28(25.9)$ & $168(36.7)$ & 0.04 & $17(27.4)$ & $11(23.9)$ & 168 & 0.1 & $18(33.3)$ & 9 (17.6) & $168(36.7)$ & 0.007 \\
\hline & $\mathrm{T} / \mathrm{T}$ & $7(6.5)$ & $23(5)$ & & $4(6.5)$ & $3(6.5)$ & $23(5)$ & & $2(3.7)$ & $5(9.8)$ & $23(5)$ & \\
\hline & $\mathrm{C}$ & $87(80)$ & $351(76.6)$ & 0.4 & $49(79)$ & $37(80)$ & $351(76.6)$ & 0.58 & $43(80)$ & $41(80)$ & $351(76.6)$ & 0.59 \\
\hline & $\mathrm{T}$ & $21(20)$ & $107(23.4)$ & & $13(21)$ & $9(20)$ & $107(23.4)$ & & $11(20)$ & $10(20)$ & $107(23.4)$ & \\
\hline \multirow[t]{5}{*}{ MMP-9 (-1562 C/T) } & $\mathrm{C} / \mathrm{C}$ & $73(70.2)$ & $303(66.2)$ & & $43(72.9)$ & $30(66.6)$ & $303(66.2)$ & & $37(71.2)$ & $33(67.3)$ & $303(66.2)$ & \\
\hline & $\mathrm{C} / \mathrm{T}$ & $27(26)$ & $136(29.7)$ & 0.51 & $15(25.4)$ & $12(26.7)$ & 136 & 0.72 & $13(25)$ & 14 (28.6) & $136(29.7)$ & 0.82 \\
\hline & $\mathrm{T} / \mathrm{T}$ & $4(3.8)$ & $19(4.1)$ & & $1(1.7)$ & $3(6.7)$ & $19(4.1)$ & & $2(3.8)$ & $2(4.1)$ & $19(4.1)$ & \\
\hline & $\mathrm{C}$ & $86(83.2)$ & $371(81)$ & 0.76 & $50(85)$ & $36(80)$ & $371(81)$ & 0.69 & $43(83)$ & $40(82)$ & $371(81)$ & 0.86 \\
\hline & $\mathrm{T}$ & $18(16.8)$ & $87(19)$ & & $9(15)$ & $9(20)$ & 87 (19) & & $9(17)$ & $9(18)$ & 87 (19) & \\
\hline \multirow[t]{5}{*}{ MMP-3 (-1171 5A/6A) } & $5 \mathrm{~A} / 5 \mathrm{~A}$ & $18(17.3)$ & $117(25.5)$ & & $12(20.4)$ & $21(46.7)$ & $117(25.5)$ & & $14(26.9)$ & $21(42)$ & $117(25.5)$ & \\
\hline & $5 \mathrm{~A} / 6 \mathrm{~A}$ & $50(48.1)$ & $226(49.3)$ & & $32(54.2)$ & $18(40)$ & $226(49.3)$ & & $27(51.9)$ & $23(46)$ & $226(49.3)$ & \\
\hline & $6 \mathrm{~A} / 6 \mathrm{~A}$ & $36(34.6)$ & $115(25.2)$ & 0.059 & $15(25.4)$ & $6(13.3)$ & 115 & 0.004 & $11(21.2)$ & $6(12)$ & $115(25.2)$ & 0.017 \\
\hline & $5 \mathrm{~A}$ & $43(41)$ & $230(50.2)$ & & $28(47)$ & $15(33)$ & $230(50.2)$ & & $25(48)$ & $18(36)$ & $230(50.2)$ & \\
\hline & $6 \mathrm{~A}$ & $61(59)$ & $228(49.8)$ & 0.11 & $31(53)$ & $30(67)$ & $228(49.8)$ & 0.041 & $27(52)$ & $32(64)$ & $228(49.8)$ & 0.073 \\
\hline
\end{tabular}

LSCC (St 0-I-II): early stages of laryngeal squamous cell carcinoma; LSCC (St III-IV): advanced stages of laryngeal squamous cell carcinoma; LSCC G1: well differentiated laryngeal squamous cell carcinoma; LSCC G2-3: moderate and poorly differentiated laryngeal squamous cell carcinoma. Bold values show statistical significance $(p<0.05)$.

$(\mathrm{OR}=1.94)$ when compared to controls (39). Tu et al., have analysed OSF and OSCC, which are prevalent among the Asian areca users, and found that the $5 \mathrm{~A} / 5 \mathrm{~A}$ genotype was associated with high risk of OSF but not of OSCC (40).

Furthermore, in studies by Hashimoto et al. and Nishizawa et al., no significant association between the MMP-3 (-1171 5A/6A) polymorphism and a risk of HNSCC was found (41-42). On the other hand, Zhang et al., have performed a meta-analysis, that included thirteen studies analysing associations between MMP-2, 3 and 9 promoter polymorphisms and ethnic, tumor site, staging and other clinical-morphological features. For MMP-3 (-1171 $5 A / 6 A)$ and MMP-9 (-1562 C/T) polymorphisms, no association was found in total meta-analysis cohort; however, in subgroup analyses based on ethnicity and tumor site, significant associations were detected between the MMP-3 $(-11715 A / 6 A)$ polymorphism and HNSCC risk in a European population and pharyngeal/laryngeal cancer. Authors have drawn attention to urge for completion of future studies with larger samples that should further evaluate the role of the MMP-3 (-1171 5A/6A) polymorphism on HNSCC risk in different populations (43).

To the best of our knowledge, the associations between MMP-3 (-1171 5A/6A) polymorphism and single LSCC have not been investigated before. Therefore, in the present study, the MMP-3 (-1171 5A/6A) gene polymorphisms and their associations with clinical and morphological manifestations in patients with LSCC and non-malignant laryngeal lesions were investigated for the first time. Our study revealed that the possibility to acquire LSCC for smokers is 7.69 times higher compared to non-smokers and for those who have MMP-3 6A/6A genotype this chance increases by 1.78 times compared to subjects who have $5 \mathrm{~A} / 5 \mathrm{~A}$ or $5 \mathrm{~A} / 6 \mathrm{~A}$ genotypes. Also, in patients with advanced LSCC the distribution of genotype MMP-3 (-1171 5A/6A) showed a significantly more frequent presence of the $6 \mathrm{~A} / 6 \mathrm{~A}$ genotype and a more frequent allele $6 \mathrm{~A}$ compared to the genotype and allele distribution of the reference group. A similar outcome was revealed after determining a significantly more frequent $6 \mathrm{~A} / 6 \mathrm{~A}$ and a rarer $5 \mathrm{~A} / 5 \mathrm{~A}$ genotype in the moderate-poorly (G2-3) differentiated LSCC patients' subgroup compared to the reference group.

It is important to note that some experimental studies have indicated an opposite understanding of the significance of MMP-3 during the carcinogenesis process. In a series of studies in mice by McCawley et al., the authors have found that MMP-3 may play a protective role in the development of SCC $(44,45)$, as treatment in MMP-3-null mice using 
chemical carcinogens enhanced tumor growth as compared to the control mice. MMP-3-null mice demonstrated a faster initial tumor growth associated with increased cell proliferation and they had more undifferentiated or early metastatic tumors with more frequent distant lung metastases. From these results, the authors proposed that MMP-3 is expressed as a protective response and plays an important role in host defence during SCC tumorigenesis. The results of these studies could partly explain the more frequent presence of MMP-3 (-1171) 6A/6A genotype and allele $6 \mathrm{~A}$ in advanced and moderate/poorly differentiated LSCC patients' group in our series. It may be presumed that a more frequent allele 6A may decrease the promoter transcription activity and MMP-3 gene expression, thus removing the possible protective role of MMP-3 during LSCC development.

In conclusion, the results of the present study demonstrate that combination of smoking and 6A/6A genotype of MMP$3(-11715 A / 6 A)$ polymorphism are associated with significantly increased odds of LSCC risk, thus confirming a presumably important role of MMP-3 (-1171) 6A/6A genotype in LSCC carcinogenesis. These results seem promising, as they may improve our understanding of the molecular events leading to LSCC formation and development. Further investigation in this field on a larger data sample is advocated.

\section{Conflicts of Interest}

The Authors have no competing interests to declare.

\section{Authors' Contributions}

All Authors (VL, VL, RL, PV, and VU) were involved in the conception and design of the present investigation. VL, RL, and PV performed laboratory tests. VL, RL, PV and VU analyzed the data. VL, RL and PV drafted the article. VU and VL revised the last version of manuscript. The final manuscript was read and approved by all authors of the study.

\section{Acknowledgements}

The Authors thank Professor Abdonas Tamosiunas for the reference group (HAPPIE) data.

\section{References}

1 Jemal A, Bray F, Center MM, Ferlay J, Ward E and Forman D: Global cancer statistics. CA Cancer J Clin 61(2): 69-90, 2011. PMID: 21296855. DOI: 10.3322/caac.20107

2 Ward EC and van As Brooks CJ: Epidemiology of head and neck cancer. In: Head and neck cancer: treatment, rehabilitation and outcomes. San Diego, Plural Publishing, pp. 10-16, 2007.

3 Pulte D and Brenner H: Changes in survival in head and neck cancers in the late 20th and early 21st century: a period analysis.
Oncologist 15(9): 994-1001, 2010. PMID: 20798198. DOI: 10.1634/theoncologist.2009-0289

4 Daugaard R, Kjaer T, Johansen C, Christiansen J, Andersen E, Nielsen AL and Dalton SO: Association between late effects assessed by physicians and quality of life reported by head-andneck cancer survivors. ActaOncol 56(2): 342-347, 2017. PMID: 28079429. DOI: 10.1080/0284186X.2016.1267873

5 Talamini R, Bosetti C, La Vecchia C, Dal Maso L, Levi F, Bidoli E, Negri E, Pasche C, Vaccarella S, Barzan L and Franceschi S: Combined effect of tobacco and alcohol on laryngeal cancer risk: a case-control study. Cancer Causes Control 13(10): 957964, 2002. PMID: 12588092.

6 Urashima M, Hama T, Suda T, Suzuki Y, Ikegami M, Sakanashi C, Akutsu T, Amagaya S, Horiuchi K, Imai Y, Mezawa H, Noya M, Nakashima A, Mafune A, Kato T and Kojima H: Distinct effects of alcohol consumption and smoking on genetic alterations in head and neck carcinoma. PLoS One 8(11): e80828, 2013. PMID: 24278325. DOI: 10.1371/journal.pone. 0080828

7 Stokes A, Joutsa J, Ala-Aho R, Pitchers M, Pennington CJ, Martin C, Premachandra DJ, Okada Y, Peltonen J, Grénman R, James HA, Edwards DR and Kähäri VM: Expression profiles and clinical correlations of degradome components in the tumor microenvironment of head and neck squamous cell carcinoma. Clin Cancer Res 16(7): 2022-2035, 2010. PMID: 20305301. DOI: 10.1158/1078-0432.CCR-09-2525

8 Freije JM, Balbín M, Pendás AM, Sánchez LM, Puente XS and López-Otín C: Matrix metalloproteinases and tumor progression. Adv Exp Med Biol 532: 91-107, 2003. PMID: 12908552. DOI: 10.1007/978-1-4615-0081-0_9

9 Nagase H, Visse R and Murphy G: Structure and function of matrix metalloproteinases and TIMPs. Cardiovasc Res 69(3): 562-573, 2006. PMID: 16405877. DOI: 10.1016/j.cardiores. 2005.12.002

10 Bellayr IH, Mu X and Li Y: Biochemical insights into the role of matrix metalloproteinases in regeneration: challenges and recent developments. Future Med Chem 1(6): 1095-1111, 2009. PMID: 20161478. DOI: 10.4155/fmc.09.83

11 Shuman Moss LA, Jensen-Taubman S and Stetler-Stevenson WG: Matrix metalloproteinases: changing roles in tumor progression and metastasis. Am J Pathol 181(6): 1895-1899, 2012. PMID: 23063657. DOI: 10.1016/j.ajpath.2012.08.044

12 Ye S: Polymorphism in matrix metalloproteinase gene promoters: implication in regulation of gene expression and susceptibility of various diseases. Matrix Biol 19(7): 623-629, 2000. PMID: 11102751.

13 Samnegård A, Silveira A, Lundman P, Boquist S, Odeberg J, Hulthe J, McPheat W, Tornvall P, Bergstrand L, Ericsson CG, Hamsten A and Eriksson P: Serum matrix metalloproteinase-3 concentration is influenced by MMP-3 -1612 5A/6A promoter genotype and associated with myocardial infarction. J Intern Med 258(5): 411-419, 2005. PMID: 16238676. DOI: 10.1111/j.13652796.2005.01561.x

14 Christopoulos TA, Papageorgakopoulou N, Ravazoula P, Mastronikolis NS, Papadas TA, Theocharis DA and Vynios DH: Expression of metalloproteinases and their tissue inhibitors in squamous cell laryngeal carcinoma. Oncol Rep 18(4): 855-860, 2007. PMID: 17786346. DOI: 10.3892/or.18.4.855

15 Colović Z, Pesutić-Pisac V, Poljak NK, Racić G, Cikojević D and Kontić M: Expression of matrix metalloproteinase-9 in 
patients with squamous cell carcinoma of the larynx. CollAntropol 37(1): 151-155, 2013. PMID: 23697266.

16 Liu RR, Li MD, Li T, Tan Y, Zhang M and Chen JC: Matrix metalloproteinase 2 (MMP2) protein expression and laryngeal cancer prognosis: a meta analysis. Int J Clin Exp Med 8(2): 2261-2266, 2015. PMID: 25932160.

17 Zhou X and Qi Y: PLGF inhibition impairs metastasis of larynx carcinoma through MMP3 downregulation. Tumour Biol 35(9): 9381-9386, 2014. PMID: 24946722. DOI: 10.1007/s13277-0142232-2

18 Peasey A, Bobak M, Kubinova R, Malyutina S, Pajak A and Tamosiunas A: Determinants of cardiovascular disease and other non-communicable diseases in Central and Eastern Europe: rationale and design of the HAPIEE study. BMC Public Health 6: 255 , 2006. PMID: 17049075. DOI: 10.1186/1471-2458-6-255

19 Liutkeviciene R, Lesauskaite V, Sinkunaite-Marsalkiene G, Zaliuniene D, Zaliaduonyte-Peksiene D and Mizariene V: The role of matrix metalloproteinases polymorphisms in age-related macular degeneration. Ophthalmic Genet 36(2): 149-155, 2015. PMID: 24079541. DOI: 10.3109/13816810.2013.838274

20 Liutkeviciene R, Lesauskaite V, Zaliaduonyte-Peksiene D, Sinkunaite-Marsalkiene G, Zaliuniene D and Mizariene V: Role of MMP-2 $(-1306 \mathrm{C} / \mathrm{T})$ polymorphism in age-related macular degeneration. Ophthalmic Genet 37(2): 170-176, 2016. PMID: 26333112. DOI: $10.3109 / 13816810.2015 .1020556$

21 Xie M, Sun Y and Li Y: Expression of matrix metalloproteinases in supraglottic carcinoma and its clinical implication for estimating lymph node metastases. Laryngoscope 114(12): 22432248, 2004. PMID: 15564854. DOI: 10.1097/01 .mlg.0000 149467.18822 .59

22 Hanata K, Yamaguchi N, Yoshikawa K, Mezaki Y, Miura M, Suzuki S, Senoo H and Ishikawa K: Soluble: EMMPRIN (extracellular matrix metalloproteinase inducer) stimulates the migration of HEp-2 human laryngeal carcinoma cells accompanied by increased MMP-2 production in fibroblasts. Arch Histol Cytol 70(5): 267-277, 2007. PMID: 18431027.

23 Wittekindt C, Jovanovic N and Guntinas-Lichius O: Expression of matrix metalloproteinase-9 (MMP-9) and blood vessel density in laryngeal squamous cell carcinomas. Acta Otolaryngol 131(1): 101106, 2011. PMID: 20873997. DOI: 10.3109/00016489.2010.506886

24 Yüce I, Bayram A, Cağlı S, Canöz O, Bayram S and Güney E: The role of CD44 and matrix metalloproteinase- 9 expression in predicting neck metastasis of supraglottic laryngeal carcinoma. Am J Otolaryngol 32(2): 141-146, 2011. PMID: 20434807. DOI: 10.1016/j.amjoto.2010.01.001

25 Mallis A, Teymoortash A, Mastronikolis NS, Werner JA and Papadas TA: MMP-2 expression in 102 patients with glottic laryngeal cancer. Eur Arch Otorhinolaryngol 269(2): 639-642, 2012. PMID: 21667117. DOI: $10.1007 / \mathrm{s} 00405-011-1625-8$

$26 \mathrm{Ra}$ HJ and Parks WC: Control of matrix metalloproteinase catalytic activity. Matrix Biol 26(8): 587-596, 2007. PMID: 17669641. DOI: $10.1016 /$ j.matbio.2007.07.001

27 Price SJ, Greaves DR and Watkins H: Identification of novel, functional genetic variants in the human matrix metalloproteinase-2 gene: role of $\mathrm{Sp} 1$ in allele-specific transcriptional regulation. J BiolChem 276(10): 7549-7558, 2001. PMID: 11114309. DOI: $10.1074 /$ jbc.M010242200

28 Vasků V, Vasků A, Tschöplová S, Izakovicová Hollá L, Semrádová V and Vácha J: Genotype association of C(-735)T polymorphism in matrix metalloproteinase 2 gene with
$\mathrm{G}(8002) A$ endothelin 1 gene with plaque psoriasis. Dermatology 204(4): 262-265, 2002. PMID: 12077518. DOI: 10.1159/ 000063355

29 Yu C, Zhou Y, Miao X, Xiong P, Tan W and Lin D: Functional haplotypes in the promoter of matrix metalloproteinase-2 predict risk of the occurrence and metastasis of esophageal cancer. Cancer Res 64(20): 7622-7628, 2004. PMID: 15492291. DOI: 10.1158/0008-5472.CAN-04-1521

30 Peng B, Cao L, Ma X, Wang W, Wang D and Yu L: Meta-analysis of association between matrix metalloproteinases 2, 7 and 9 promoter polymorphisms and cancer risk. Mutagenesis 25(4): 371379, 2010. PMID: 20360147. DOI: 10.1093/mutage/geq015

31 Kim SK, Kang SW, Park HJ, Ban JY, Oh CH, Chung JH, Oh IH, Cho KB and Park MS: Meta-analysis of association of the matrix metalloproteinase $2(-735 \mathrm{C} / \mathrm{T})$ polymorphism with cancer risk. Int J ClinExp Med 8(10): 17096-17101, 2015. PMID: 26770302.

32 Zhang B, Ye S, Herrmann SM, Eriksson P, de Maat M, Evans A, Arveiler D, Luc G, Cambien F, Hamsten A, Watkins H and Henney AM: Functional polymorphism in the regulatory region of gelatinase B gene in relation to severity of coronary atherosclerosis. Circulation 99(14): 1788-1794, 1999. PMID: 10199873. DOI: 10.1161/01.cir.99.14.1788

33 Vairaktaris E, Vassiliou S, Nkenke E, Serefoglou Z, Derka S, Tsigris C, Vylliotis A, Yapijakis C, Neukam FW and Patsouris E: A metalloproteinase-9 polymorphism which affects its expression is associated with increased risk for oral squamous cell carcinoma. Eur J Surg Oncol 34(4): 450-455, 2008. PMID: 17498910. DOI: 10.1016/j.ejso.2007.03.024

$34 \mathrm{Tu}$ HF, Wu CH, Kao SY, Liu CJ, Liu TY and Lui MT: Functional -1562 C-to-T polymorphism in matrix metalloproteinase-9 (MMP-9) promoter is associated with the risk for oral squamous cell carcinoma in younger male areca users. J Oral Pathol Med 36(7): 409-414, 2007. PMID: 17617834. DOI: 10.1111/j.1600-0714.2007.00552.x

35 Chaudhary AK, Pandya S, Mehrotra R, Singh M and Singh M: Role of functional polymorphism of matrix metalloproteinase-2 $(-1306 \mathrm{C} / \mathrm{T}$ and $-168 \mathrm{G} / \mathrm{T})$ and MMP-9 $(-1562 \mathrm{C} / \mathrm{T})$ promoter in oral submucous fibrosis and head and neck squamous cell carcinoma in an Indian population. Biomarkers 16(7): 577-586, 2011. PMID: 21958210. DOI: 10.3109/1354750X.2011.609602

36 Liu D, Guo H, Li Y, Xu X, Yang K and Bai Y: Association between polymorphisms in the promoter regions of matrix metalloproteinases (MMPs) and risk of cancer metastasis: a meta-analysis. PLoS One 7(2): e31251, 2012. PMID: 22348060. DOI: $10.1371 /$ journal.pone.0031251

37 Nasr HB, Mestiri S, Chahed K, Bouaouina N, GabboujS, Jalbout $\mathrm{M}$ and Chouchane L: Matrix metalloproteinase-1 (-1607) 1G/2G and -9 (-1562) C/T promoter polymorphisms: susceptibility and prognostic implications in nasopharyngeal carcinomas. Clin Chim Acta 384(1-2): 57-63, 2007. PMID: 17599818. DOI: 10.1016/j.cca.2007.05.018

38 Ye S, Eriksson P, Hamsten A, KurkinenM, Humphries SE and Henney AM: Progression of coronary atherosclerosis is associated with a common genetic variant of the human stromelysin-1 promoter which results in reduced gene expression. J Biol Chem 271(22): 13055-13060, 1996. PMID: 8662692. DOI: $10.1074 /$ jbc.271.22.13055

39 Chaudhary AK, Singh M, Bharti AC, Singh M, Shukla S, Singh AK and Mehrotra R: Synergistic effect of stromelysin-1 (matrix 
metalloproteinase-3) promoter (-1171 5A->6A) polymorphism in oral submucous fibrosis and head and neck lesions. BMC Cancer 10: 369, 2010. PMID: 20630073. DOI: 10.1186/14712407-10-369

40 Tu HF, Liu CJ, Chang CS, Lui MT, Kao SY, Chang CP and Liu TY: The functional (-1171 5A-->6A) polymorphisms of matrix metalloproteinase 3 gene as a risk factor for oral submucous fibrosis among male areca users. J Oral Pathol Med 35(2): 99103, 2006. PMID: 16430740. DOI: 10.1111/j.1600-0714.2006. 00370.x

41 Hashimoto T, Uchida K, Okayama N, Imate Y, Suehiro Y, Hamanaka Y, Ueyama Y, Shinozaki F, Yamashita H and Hinoda Y: Association of matrix metalloproteinase (MMP)-1 promoter polymorphism with head and neck squamous cell carcinoma. Cancer Lett 211(1): 19-24, 2004. PMID: 15194213. DOI: $10.1016 /$ j.canlet.2004.01.032

42 Nishizawa R, Nagata M, Noman AA, Kitamura N, Fujita H, Hoshina H, Kubota T, Itagaki M, Shingaki S, Ohnishi M, Kurita H, Katsura K, Saito C, Yoshie H and Takagi R: The 2G allele of promoter region of matrix metalloproteinase- 1 as an essential pre-condition for the early onset of oral squamous cell carcinoma. BMC Cancer 7: 187, 2007. PMID: 17919326. DOI: $10.1186 / 1471-2407-7-187$
43 Zhang C, Li C, Zhu M, Zhang Q, Xie Z, Niu G, Song X, Jin L, Li G and Zheng H: Meta-analysis of MMP2, MMP3, and MMP9 promoter polymorphisms and head and neck cancer risk. PLoS One 8(4): e62023, 2013. PMID: 23637955. DOI: 10.1371/ journal.pone.0062023

44 McCawley LJ, Crawford HC, King LE Jr, Mudgett J and Matrisian LM: A protective role for matrix metalloproteinase-3 in squamous cell carcinoma. Cancer Res 64(19): 6965-6972, 2004. PMID: 15466188. DOI: 10.1158/0008-5472.CAN-04-0910

45 McCawley LJ, Wright J, LaFleur BJ, Crawford HC and Matrisian LM: Keratinocyte expression of MMP3 enhances differentiation and prevents tumor establishment. Am J Pathol 173(5): 15281539, 2008. PMID: 18832569. DOI: 10.2353/ajpath.2008.080132

Received September 22, 2019

Revised October 10, 2019

Accepted October 18, 2019 